\title{
Negative pressure wound therapy in a chronic radiation dermatitis of the scalp.
}

\author{
Tomasz Banasiewicz, Wojciech Francuzik
}

\section{CASE REPORT}

\begin{abstract}
The adverse reactions of late tissue damage in irradiated patients may range from bothersome symptoms that negatively affect their quality of life to severe life-threatening complications. We describe the case of a female patient, EM, 54 years old who presented with chronic radioation dermatitis on her scalp following radiotherapy $(60 \mathrm{~Gy}$ in 30 fractions over 6 weeks) for a meningioma of the right frontal region.

We decided to introduce the negative pressure wound therapy (NPWT) with a portable Avelle ${ }^{\mathrm{TM}}$ system (Convatec; UK) in a continuous therapy mode with $\mathbf{- 8 0} \mathbf{~ m m H g}$ vacuum. The dressing was subsequently applied directly on the skin of the skull and braced with extra adhesive strips and changed every 3 days ( 3 changes in total). During the therapy we didn't observed any side-effects or complications, system was well tolerated by the patient and lead to the improvement of the wound promoting the granulation and decreasing the exudate from the wound.
\end{abstract}

Keywords - venous ulcers, negative pressure wound therapy, chronic wound, chronic venous insufficiency, skin graft, silver, pain

\section{INTRODUCTION}

$\mathbf{S}$ EVERE skin, soft tissue and bone infections are delayed complications of irradiation of the skull in the course skull and brain tumor radiotherapy 1 The adverse reactions of late tissue damage in irradiated patients may range from bothersome symptoms that negatively affect their quality of life to severe life-threatening complications. ${ }^{[2}$ In patients with advanced necrosis it may lead to severe tissue and bone defects, with vast exposure of the dura mater surface and severe infections $\sqrt[3]{3}$ Up to $95 \%$ of patients who undergo irradiation develop adverse skin lesions. ${ }^{4}$ Treatment of the radiotherapy induced skin, soft tissue, and bone adverse lesions is complicated, therefore prolonging the healing process and negatively impacting the patient's quality of life ${ }^{5}$ Topical interventions to prevent acute radiation dermatitis in head and neck cancer patients are still not effective and not routinely used 6 This report follows the recommendations from the CARE Statement for writing case reports. ${ }^{[7}$

Manuscript received 26.03.2018; revised 31.03.2018. This work did not receive any financial support. Authors declare no conflict of interest.

Author affiliations: Chair and Department of the General, Endocrinological Surgery and Gastrointestinal Oncology. On examination , (TB) ; Department of Dermatology, Charité - Universitätsmedizin Berlin, corporate member of Freie Universität Berlin, Humboldt-Universität zu Berlin, and Berlin Institute of Health, (WF)

*Correspondence to: Tomasz Banasiewicz: tbanasiewicz@op.pl
Table I

CHARACTERISTICS OF THE PATIENTS

\begin{tabular}{ll}
\hline Date & Event \\
\hline $10 / 2016$ & The diagnosis of a meningioma of the right frontal region \\
$11 / 2016$ & The neurosurgical local tumor resection \\
$12 / 2016$ & Beginning of the Radiotherapy \\
$01 / 2017$ & Radiotherapy concluded (60 Gy in total) Patient observed \\
& redness of the scar and pruritus \\
$10 / 2017$ & Patient observed redness of the scar and pruritus \\
$11 / 2017$ & First ulceration formed on the scalp \\
$11 / 2017$ & Subsequent ulceration formed in the next weeks \\
$11 / 2017$ & Topical therapy sine effectu \\
$12 / 2017$ & Hyperbaric therapy sine effectu \\
$09 / 01 / 2018$ & Initiation of the negative pressure wound therapy \\
$18 / 01 / 2018$ & Significant improvement of the clinical symptoms
\end{tabular}

\section{PATIENT INFORMATION}

We describe the case of a female patient, EM, 54 y.o. who presented with a chronic non-healing wound on her scalp. The patient was diagnosed with a brain tumor in 2016 (meningioma of the right frontal region) and subsequently treated with the neurosurgical local resection followed by the postoperative radiotherapy (60 Gy in 30 fractions over 6 weeks) with good results, no side effects. The oncological therapeutic effect was satisfactory and at the time of the ambulatory admission at our department $(1 / 2018)$ the patient showed no signs of recurrence of the malignancy.

In October 2017, the patient observed an irritation of the skin in the postoperative wound (scar) with itching and redness. Symptoms occurred 10 months after the last irradiation session. A few weeks later, the lesions transformed into a single ulcer $2 \mathrm{~cm} \mathrm{x} 4 \mathrm{~cm}$, and in the subsequent weeks additional ulcerations occurred. Patient reported for a visit in our office in January 2018.

The patients presented no other pathologies and concomitant diseases, no familial history of neoplasia, nor signs of cachexia were present. The patient didn't smoke and use alcohol.

\section{ClinicAl Findings}

In January 2018 patient was admitted to the outpatient Department of the General, Endocrinological Surgery and Gastrointestinal Oncology. On examination, there were 3 distinct longitudinal ulcers in various size, ranging between 2 
$\mathrm{cm}$ and $6 \mathrm{~cm}$ in width. Ulcerations increased in depth and size in 2 preceding weeks exposing the bone with necrosis and soft tissue inflammation at the lesion borders (Fig. 1). The skin of the scalp appeared poikilodermic with telangiectases, hypo- and hyper-pigmentation, and atrophy. A yellowish hue indicating radiation elastosis was present. The wound bed was covered with a thick yellowish exudate secreting into the wound dressing (Fig. 2). The chronic radiation dermatitis was diagnosed based on a clinical examination and patient's medical history.

\section{THERAPEUTIC INTERVENTION}

Before the patient presented in our clinic, she underwent lesion debridement and the dense secretion was evacuated from the wound bed. Subsequently she was treated with the standard wound dressings $(0,1 \%$ octenidine dihydrochloride and $2 \%$ phenoxyethanol wash and alginate wound dressings), changed 2 times daily without improvement. In December 2017, 6 weeks of hyperbaric therapy ( 5 x 60 minute sessions per week with 1,4-1,8 ATA pressure chamber) was introduced, again, without significant improvement.

We decided to introduce the negative pressure wound therapy (NPWT) with a portable Avelle ${ }^{\mathrm{TM}}$ system (Convatec; UK). The localization of the wounds proved problematic for the wound dressing application as it was difficult to provide a reliable seal for the negative pressure therapy system. We chose a Hydrofiber ${ }^{\mathrm{TM}}$ wound dressing of $12 \times 21$ $\mathrm{cm}$ (Avelle ${ }^{\mathrm{TM}}$, Convatec, UK), cut in the middle to reduce its size and make the application easier. To provide a better seal for the system, a sealing "frame" of the stoma paste (Stomahesive, Convatec) was put on the surface of the Hydrofiber ${ }^{\mathrm{TM}}$ (Fig. 3). The dressing was subsequently applied directly on the skin of the skull and braced with extra adhesive strips, especially at the side that was previously cut, to secure it in place (Fig. 4).

We set the device initially to provide continuous mode therapy with $-80 \mathrm{mmHg}$ vacuum. We changed the wound dressing every 3 days ( 3 changes in total). At the first wound dressing change, we could still observe the signs of inflammation with pus secretion, erythematous skin irritation and the oedema of the soft tissues (Fig. 5). After another 3 days the oedema decreased significantly, similarly to the exudate secretion and the skin erythema. After the last dressing removal ( 9 days after the initiation of the NPWT) we observed no secretion, no soft tissue oedema, and minimal skin erythema (Fig. 6). Patient did not report pain or itching (which were moderately severe before). Patient was satisfied with the outcome and we decided together with the patient to repeat the course of the hyperbaric therapy where we referred her. The patient used the standard topical skin care with hypoallergenic, $10 \%$ urea containing emollients thereafter.

\section{DISCUSSION}

Skin lesions in the course of radiotherapy are a common side effect, observed in various localizations and regions. Every year, 1.2 million cancer patients receive radiation therapy in the United States only. Late radiation-tissue-injury

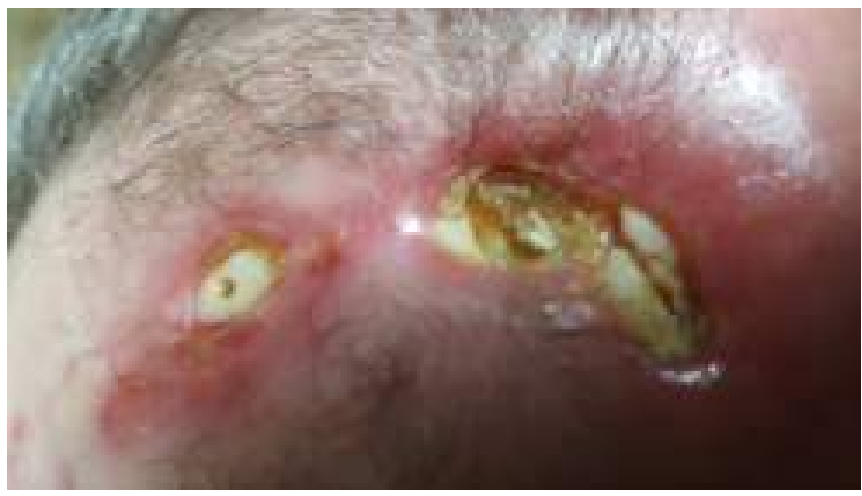

Figure 1. The scalp on admission the our department. Radiodermatitis with multiple skin lesions visible.

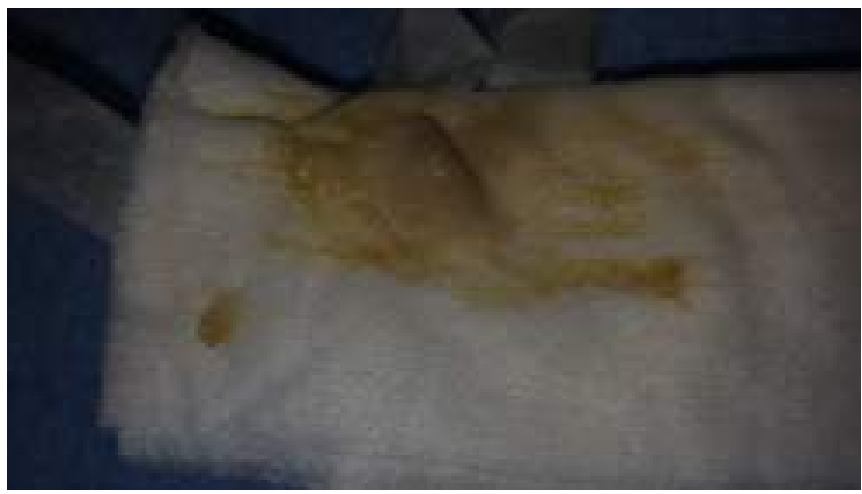

Figure 2. The standard gauze wound dresing after dressing change. Notice the significant amount of exudate.

occurs in an estimated 5-15\% of these patients. Tissue injury can include skin necrosis, which can lead to chronic nonhealing wounds. ${ }^{9}$ In severe cases, depending on localization, soft tissue necrosis, inflammation, and infection can also occur. Craniofacial radiation can lead to severe complicated wounds and, if used in childhood, to various abnormalities, from softtissue deficiency to osseous deformities $[10$

One of the effective method of treatment of complicated wounds is negative pressure wound therapy (NPWT). NPWT leads to the fast elimination of the septic conditions, improving the tissue vascularization, stimulating the fibroblast proliferation and migration, managing the wound exudation, and accelerating wound healing ${ }^{11}$ The use of this method has also been proved to improve the treatment results of severe surgical infections in neurosurgery. ${ }^{12}$ One of the earliest reports describing treatment with vacuum assisted closure (VAC) therapy on complex cranial wounds was published by Andrews et al., where two patients with traumatic scalp injuries were successfully treated without any complications. 13 There are reports in the literature that describe the use of NPWT in scalp defects with exposed periosteum, and fewer reports describing defects in periosteum with exposed dura mater 3 [14

The NPWT is a more effective therapy for bone-exposed wounds than conventional gauze dressing therapy ${ }^{[15}$ It can promote bone-exposed-wounds to heal by increasing collagen contents and angiogenesis while reducing inflammatory cells 


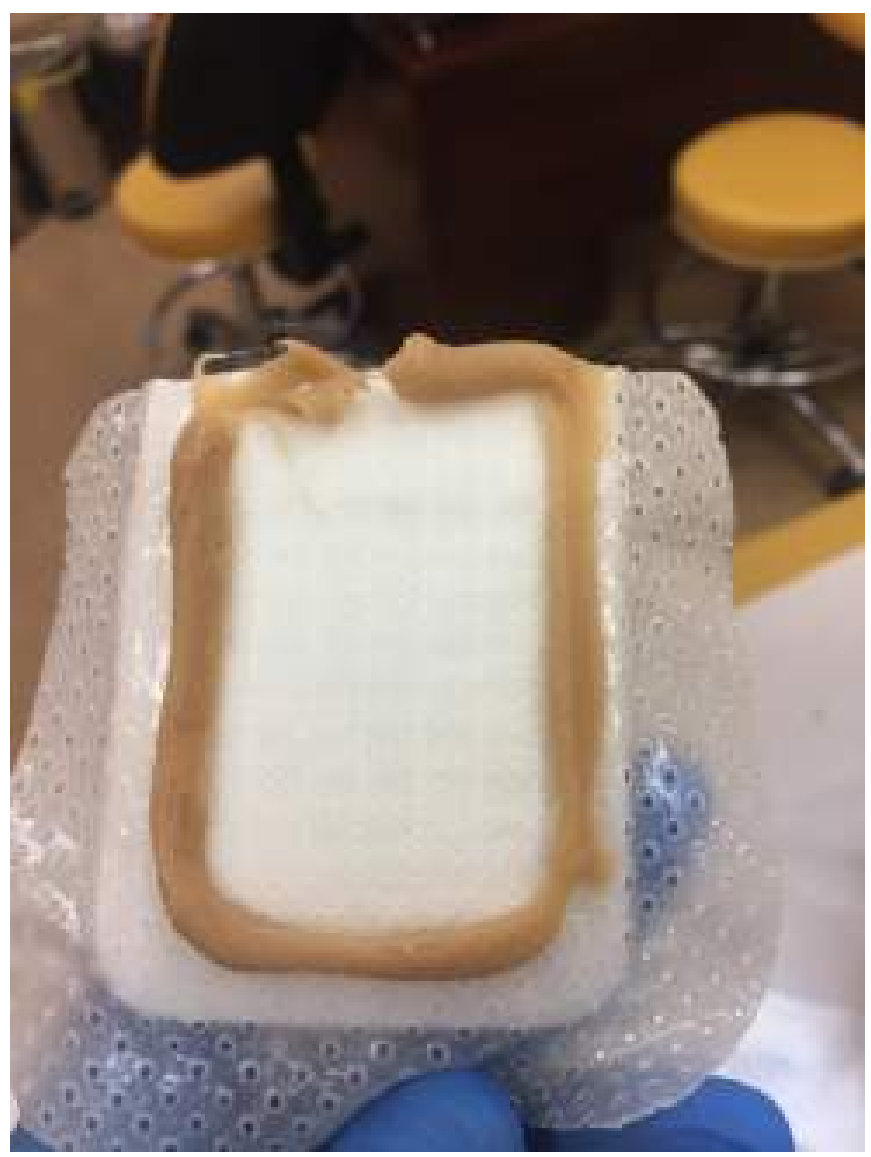

Figure 3. The Hydrofiber ${ }^{\mathrm{TM}}$ negative pressure wound dressing with a sealing stoma paste "frame".

infiltration, reducing wound infection rates, and inducing an ordered collagen arrangement. ${ }^{[15}$ In the head region NPWT can also be effectively used in patients with osteoradionecrosis. 16

Described NPWT therapies in head and neck wounds mainly used the standard vacuum devices with canisters. Many studies in the last years confirmed the effectiveness of the disposable, canister-less negative pressure wound therapy system ${ }^{17}$ The results of the literature reviews show, that the portable, canisterless NPWT system meets or exceeds healing rates previously reported in the literature for canister-based systems. ${ }^{17}$ This simple device enhancement offers a more portable NPWT option, particularly effective in the treatment of shallow wounds 18 and increases patient compliance.

In our case, we used the Avelle ${ }^{\mathrm{TM}}$ (Convatec; UK) system, recently introduced into the medical market $\left[\begin{array}{l}19 \\ 20\end{array}\right.$ Avelle $^{\mathrm{TM}}$ uses Hydrofiber ${ }^{\mathrm{TM}}$ dressings and the pressure used in therapy is a continuous $-80 \mathrm{mmHg}$. The very common technical problem with application of the dressings, also NPWT dressing, is the curvature of the body region. Location of the NPWT system on the skull was uncertain, therefore, to avoid decompression, we decided to use the stoma paste. This modification, improved the seal and prolonged the time between wound dressing changes as described previously 21 [22 It is most commonly combined with standard "big wound dressings" based on the polyurethane sponge and canister-

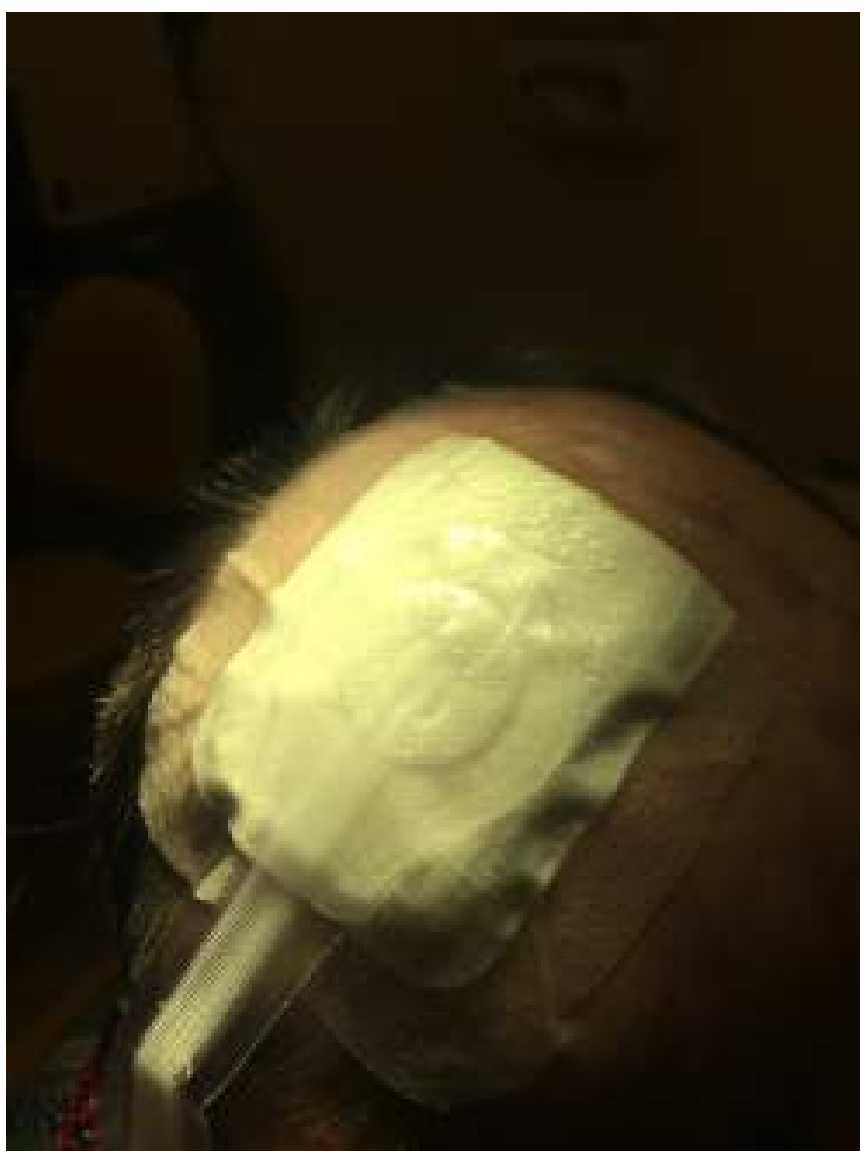

Figure 4. The scalp after introducing the portable negative pressure wound therapy system

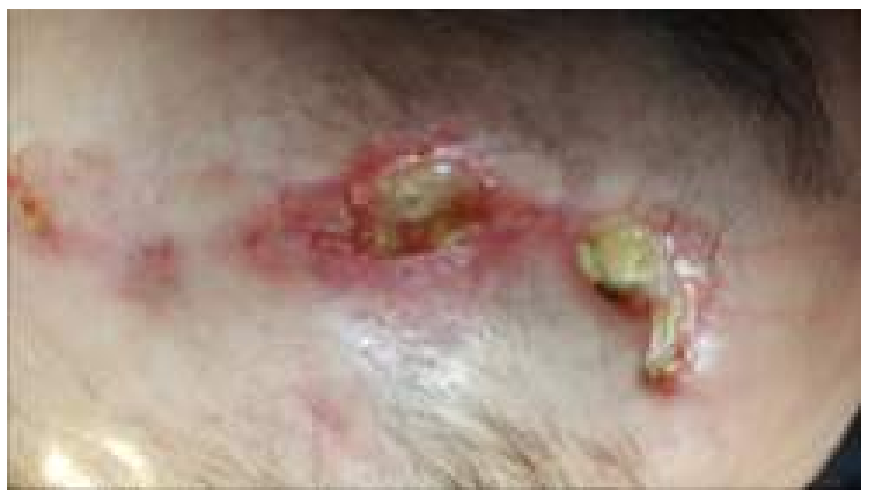

Figure 5. Therapeutic outcome after 2 wound dressing changes and 6 days of portable NPWT in a continuous mode of $-80 \mathrm{mmHg}$.

based systems. There portable dressing systems may also be easily cut to obtain the optimal form and size for the wound bed. It is necessary to remember, that in such case the exudate collection volume will be lower, and the surgeon must account for that.

During the therapy we didn't observed any side-effects or complications, system was well tolerated by the patient and lead to the improvement of the wound promoting the granulation and decreasing the exudate from the wound.

To conclude, the portable NPWT can be successfully used in cases of complicated skull wounds with soft tissue and 


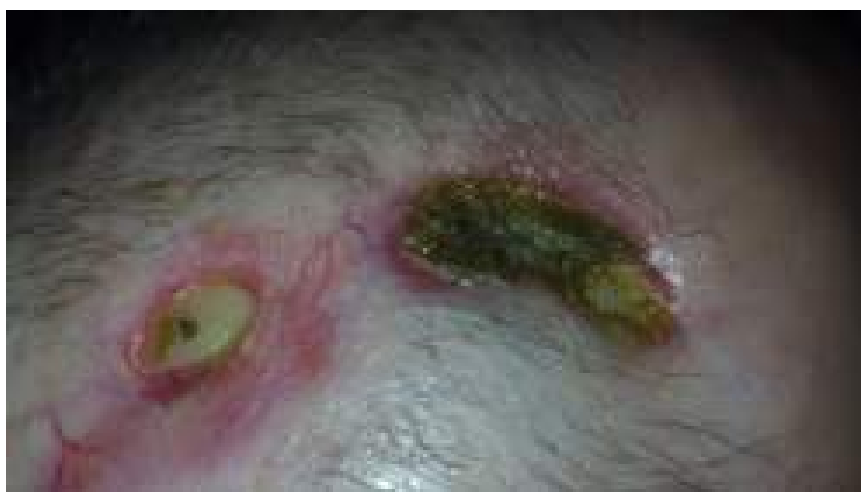

Figure 6. Therapeutic outcome after 3 wound dressing changes and 9 days of portable NPWT in a continuous mode of $-80 \mathrm{mmHg}$.

bone defects. However, there are no data to determine the efficacy of this method relative to other wound healing methods. It should be remembered, however, that the NPWT allows to combine various therapeutic methods and poses a new option for the treatment of difficult no-healing skull wounds.

\section{INFORMED CONSENT}

The patient provided an informed consent for the publication of this case along with unidentifiable photographic material.

\section{REFERENCES}

[1] S. T. Gray, A. Lin, W. T. Curry, F. G. Barker, P. Busse, A. Sanan, D. G. Deschler, and D. T. Lin, "Delayed complications after anterior craniofacial resection of malignant skull base tumors," Journal of neurological surgery. Part B, Skull base, vol. 75, no. 2, p. 110, 2014.

[2] K. A. Hutcheson, J. S. Lewin, D. A. Barringer, A. Lisec, G. B. Gunn, M. W. Moore, and F. C. Holsinger, "Late dysphagia after radiotherapybased treatment of head and neck cancer," Cancer, vol. 118, no. 23, pp. 5793-5799, 2012.

[4] M. Spałek, "Chronic radiation-induced dermatitis: challenges and solutions," Clinical, cosmetic and investigational dermatology, vol. 9, p. 473, 2016.

[5] S. Bostock and J. Bryan, "Radiotherapy-induced skin reactions: assessment and management," British Journal of Nursing, vol. 25, no. 4, pp. S18-S24, 2016.

[6] E. B. Ferreira, C. I. Vasques, R. Gadia, R. J. Chan, E. N. S. Guerra, L. A. Mezzomo, G. D. L. Canto, and P. E. D. dos Reis, "Topical interventions to prevent acute radiation dermatitis in head and neck cancer patients: a systematic review," Supportive Care in Cancer, vol. 25, no. 3, pp. 1001-1011, 2017.

[7] J. J. Gagnier, G. Kienle, D. G. Altman, D. Moher, H. Sox, and D. Riley, "The care guidelines: consensus-based clinical case reporting guideline development," Journal of medical case reports, vol. 7, no. 1, p. 223, 2013.
[3] T. BANASIEWICZ, B. SOKÓ£, J. BILSKA-STOKŁOSA, B. MAŃKOWSKI, K. ZASTAWNA, W. LEDWOSIŃSKI, W. LIBERT, and K. OSMOLA, "Zastosowanie urgotul $®$ ag/silver jako warstwy pośredniej w leczeniu zakażenia tkanek miẹkkich i kości czaszki z wykorzystaniem terapii podciśnieniowej-opis przypadku." Leczenie Ran, vol. 14, no. 1, 2017.

[8] J. Lee, W. Park, D. H. Choi, S. J. Huh, I.-R. Kim, D. Kang, and J. Cho, "Patient-reported symptoms of radiation dermatitis during breast cancer radiotherapy: a pilot study," Quality of Life Research, vol. 26, no. 7, pp. 1713-1719, 2017.

[9] Z. Borab, M. D. Mirmanesh, M. Gantz, A. Cusano, and L. L. Pu, "Systematic review of hyperbaric oxygen therapy for the treatment of radiation-induced skin necrosis," Journal of Plastic, Reconstructive \& Aesthetic Surgery, vol. 70, no. 4, pp. 529-538, 2017.

[10] K. A. Allam, A. A. Lim, A. Elsherbiny, J. P. Bradley, and H. K. Kawamoto, "Radiation-induced craniofacial deformities: A new classification and management algorithm," Journal of Plastic, Reconstructive \& Aesthetic Surgery, vol. 66, no. 8, pp. 1088-1095, 2013.

[11] A. K. Powers, M. T. Neal, L. C. Argenta, J. A. Wilson, A. J. DeFranzo, and S. B. Tatter, "Vacuum-assisted closure for complex cranial wounds involving the loss of dura mater: report of 5 cases," Journal of neurosurgery, vol. 118, no. 2, pp. 302-308, 2013.

[12] U. Subotic, W. Kluwe, and V. Oesch, "Community-associated methicillin-resistant staphylococcus aureus-infected chronic scalp wound with exposed dura in a 10-year-old boy: vacuum-assisted closure is a feasible option: case report," Neurosurgery, vol. 68, no. 5, pp. E1481-E1484, 2011.

[13] B. T. Andrews, R. B. Smith, D. P. Goldstein, and G. F. Funk, "Management of complicated head and neck wounds with vacuumassisted closure system," Head \& neck, vol. 28, no. 11, pp. 974-981, 2006.

[14] O. Ahmed, C. M. Storey, S. Zhang, M. R. Chelly, M. S. Yeoh, and A. Nanda, "Vacuum-assisted closure of necrotic and infected cranial wound with loss of dura mater: a technical note," Surgical neurology international, vol. 6, 2015.

[15] L. Chen, G. Li, S. Liu, X. Ma, X. Li, Y. Su, and S. Guo, "Comparison of negative pressure wound therapy and conventional therapy for cranial bone-exposed wounds in rabbits," Annals of plastic surgery, vol. 79, no. 4, pp. 397-403, 2017.

[16] D.-m. Zhang, Z.-h. Yang, P.-1. Zhuang, Y.-y. Wang, W.-1. Chen, and B. Zhang, "Role of negative-pressure wound therapy in the management of submandibular fistula after reconstruction for osteoradionecrosis," Journal of Oral and Maxillofacial Surgery, vol. 74, no. 2, pp. 401-405, 2016.

[17] M. Malmsjö, E. Huddleston, and R. Martin, "Biological effects of a disposable, canisterless negative pressure wound therapy system," Eplasty, vol. 14, 2014.

[18] T. E. Serena and J. S. Buan, "The use of a novel canister-free negativepressure device in chronic wounds: A retrospective analysis," Advances in skin \& wound care, vol. 29, no. 4, pp. 165-168, 2016.

[19] F. Duteille, E. Sharp, and C. Traynor, "The avelle npwt system," Journal of wound care, vol. 27, no. Sup3, pp. S14-S16, 2018.

[20] E. Sharp, "Avelle npwt system: frequently asked questions." Journal of wound care, vol. 27, no. Sup3, p. S24, 2018.

[21] M. J. Karadsheh, J. Nelson, and R. Wilcox, "The application of skin adhesive to maintain seal in negative pressure wound therapy." Wounds: a compendium of clinical research and practice, vol. 27, no. 9, pp. 244-248, 2015.

[22] M. Kicińska, D. Błażejewska, and T. Banasiewicz, "Negative pressure wound therapy use in the treatment of patient with an active process of anal cancer in order to the further treatment-case report." Negative

Pressure Wound Therapy Journal, vol. 3, no. 1, 2016. 